\title{
The effects of situational and personal variables on vertical autokinesis
}

\author{
MORGAN WORTHY AND GAY KAHN, DEPARTMENT OF \\ PSYCHOLOGY, GEORGIA STATE COLLEGE, Atlanta, Ga. \\ 30303
}

Subjects in an autokinetic situation reported after each trial whether the stimulus light had moved up or down. More upward movement was reported following a failure experience than following a success experience. Also more upward movement was reported when the height of the light was about eye level than when it was below eye level. Differences in the name assigned to the stimulus light by $E$ had no effect on the direction of movement reported.

It has been demonstrated that the direction of movement reported in the autokinetic (AK) situation is influenced by stimulus variables and personal variables. Toch (1962) found that a stimulus light in the shape of an arrow tended to be seen as moving in the direction indicated by the point of the arrow. A similar effect has been obtained with a light of an ambiguous shape by suggesting to the $S$ that the light represented a particular object. Comalli, Weiner, \& Wapner (1957) used a light which could be perceived as either a balloon or a parachute. When the light was called a balloon by the $\mathrm{E}$, more upward movement was reported than when it was called a parachute. Another aspect of the stimulus which has been found to influence the direction of movement reported is the position of the light in the visual field. Luchins (1954) reported that when a light was presented in the periphery of the visual field the light tended to be perceived as moving in the peripheral direction.

In the present study two aspects of the stimulus were varied in an attempt to extend the above findings. The effect of stimulus meaning on reported movement was studied by varying the name assigned by the $E$ to the stimulus. For some of the Ss the light was called a "Jimmy Light"; for the other Ss it was called a "Suzy Light." It was expected that cultural expectations of more dominant behavior in males than in females would result in more upward movement being reported when the light was called "Jimmy" than when it was called "Suzy." In addition to differences in the name assigned to the light, the height of the light from the floor was varied. In one condition the light was placed at about eye level; in another condition it was placed below eye level. It was expected that less upward movement would be reported when the light was at the lower level than when it was at eye level.

It has been shown that what is perceived may be a function not only of the stimulus, but also of characteristics of the perceiver. Studies which have successfully demonstrated the effect of personal variables on the direction of AK movement reported have dealt with stable characteristics such as sex (Fisher, 1962) and achievement orientation (Fisher, 1961). In the present study a temporary personal condition, feelings of success or failure, was varied. Each S's AK perceptions were obtained immediately following a success experience and immediately following a failure experience. It was hypothesized that Ss would report more upward movement after a failure experience than after a success experience. This hypothesis was derived from the expectation that Ss would tend to contrast the movement of the light with their own temporary feelings.

Subjects. The Ss were 48 female undergraduates at Georgia State College. They were fulfilling a requirement of the introductory psychology course.

Apparatus. The AK stimulus was a pinpoint of light provided by a $.25 \mathrm{~W}$ night light wrapped with black tape. Except for the AK light, whicli was visible through a hole in the tape, the room was totally dark. The $S$ sat $12 \mathrm{ft}$ from the light. The light remained on for $15 \mathrm{sec}$ on each AK trial.

Procedure and Design. Each $S$ was first given a $7 \mathrm{~min}$ verbal problemsolving test and led to believe that she had either succeeded or failed on the test. She then was given $15 \mathrm{AK}$ trials to which she reported whether the light had first moved up or down. Another verbal problem solving test was then given, and those who had supposedly failed on the first test were led to believe that they succeeded on the second test and vice versa. The $S$ then was
Table 1

Mean Number of Autokinetic Upward Movements Minus Downward Movements Reported

\begin{tabular}{cccc} 
Height of Light & Name Assigned & \multicolumn{2}{c}{$\begin{array}{c}\text { Immediately Prior } \\
\text { Experiences }\end{array}$} \\
\cline { 3 - 4 } from Floor & to Light & Success & Failures \\
\hline \multirow{2}{*}{$45 \mathrm{in.}$} & Suzy & 5.250 & 8.500 \\
& Jimmy & 5.500 & 6.750 \\
$29 \mathrm{in.}$ & Suzy & 1.625 & 4.333 \\
& Jimmy & 1.775 & 5.250 \\
\hline
\end{tabular}

given 15 additional AK trials. All Ss were given both a success and a failure experience; the order of which experience was provided first was counterbalanced.

The name assigned to the light by the $\mathrm{E}$ was systematically varied. In one condition it was called a "Jimmy Light"; in the other condition it was called a "Suzy Light." The height of the light from the floor was also varied. In one condition the height was 45 in. (about eyelevel); in the other condition it was 29 in. from the floor.

The experimental design was a 2 by 2 by 2 factorial design in which success-failure, height of light, and the name of light were made orthogonal to each other.

Results and Discussion. The dependent measure was a difference score computed by subtracting the number of downward movements reported during the 15 trial series from the number of upward movements reported. The means for the different experimental groups are presented in Table 1. The difference between the "Jimmy Light" group ( $M=4.819)$ and "Suzy Light" group (M $=4.927)$ was not significant $(\mathrm{F}<1.00$, df $=1 / 44)$. However, the analysis showed that significantly more upward movement was reported when the light was $45 \mathrm{in}$. above the floor $(\mathrm{M}=6.5)$ than when it was 29 in. above the floor $(M=3.246)(F=4.830$, df $=$ $1 / 44, p<.05)$. In addition it showed that significantly more upward movement was reported after the failure experience $(\mathrm{M}=$ $6.208)$ than after the success experience $(M=3.538)(F=11.957$, $\mathrm{df}=1 / 44, \mathrm{p}<.01)$. None of the interactions were significant.

The results of this experiment indicate that assigning masculine or feminine names to the stimulus has no apparent differential effect on the perception of vertical AK movement. Ss were aware of the name assigned as evidenced by the observation that many $\mathrm{Ss}$ referred to the light as "he" or "she." Perhaps naming loses its effect on reported AK movement when the shape of the light is totally ambiguous as it was in this experiment.

The results also indicate that the height of the light in relation to the $\mathrm{S}$ significantly affects the direction of vertical movement perceived. More upward movement is reported at the higher level than at the lower level. Even at the lower level, however, more upward than downward movement is reported.

Finally, the results indicate that a very significant determinant of direction of AK movement is the immediately prior experience of the $S$. More upward movement is reported following failure than following success. This finding may be interpreted as reflecting a tendency of the $S$ to contrast the movement of the light with his own temporary feelings. The $S$ serves as one anchor in the AK situation such that when he feels "low" the light is seen as moving up and when he feels "high" the light is seen as moving down.

\section{REFERENCES}

COMALLI, P. E. Jr., WERNER, H., \& WAPNER, S. Studies in physionomic perception: IIl. Effect of directional dynamics and meaning induced sets on autokinetic motions. J. Psychol., 1957, 43, 389-399.

FISHER, S. Achievement themes and directionality of autokinetic movement. J. abnorm. soc. Psychol., 1961, 63, 64-68.

FISHER, S. Developmental sex differences in right-left perceptual directionality. Child. Develpm., 1962, 33(2), 463-468.

LUCHINS, A. S. The autokinetic effect in central and peripheral vision. $J$. Gen. Psychol., 1954, 50, 39-44. 